\title{
Enterotoxigenic Clostridium perfringens as a cause of sporadic cases of diarrhoea
}

\author{
O. MPAMUGO, T. DONOVAN* and M. M. BRETT†
}

Public Health Laboratory Service, Food Hygiene Laboratory, Central Public Health Laboratory, 61 Colindale Avenue, London NW9 5 HT and "Public Health Laboratory, Ashford, Kent

\begin{abstract}
Summary. The purpose of this study was to investigate the incidence of cases of sporadic diarrhoea associated with enterotoxigenic Clostridium perfringens. Cases were identified by detection of $C$. perfringens enterotoxin with the Oxoid RPLA kit, with confirmation by ELISA, in faecal specimens from isolated incidents of diarrhoea and from which no other enteropathogen had been isolated. In a 2-month study, $65(18 \%)$ of 370 specimens were enterotoxin positive. There was no predominant age group or sex in the enterotoxin-positive group, but a higher proportion ( $79 \%$ ) was resident in the community than were enterotoxinnegative cases $(34 \%)$. Only four of the 65 enterotoxin-positive patients had received antibiotic therapy. Spore counts in most enterotoxin-positive patients were $<10^{5} / \mathrm{g}$, indicating that detection of high numbers of $C$. perfringens is not useful in determining the aetiology of sporadic diarrhoea. Diagnosis should be confirmed by the detection of enterotoxin, but further work is required to assess whether an acceptable accuracy is obtained with the RPLA kit or whether ELISA is needed in all cases.
\end{abstract}

\section{Introduction}

It is well recognised that outbreaks of foodborne diarrhoea are caused by enterotoxigenic Clostridium perfringens. ${ }^{1}$ More recently, the organism has been implicated as a cause of antibiotic-associated diarrhoea, ${ }^{2}$ infectious diarrhoea ${ }^{3}$ and sporadic diarrhoea. ${ }^{4,5}$ The aim of this study was to investigate the prevalence of sporadic cases of diarrhoea associated with $C$. perfringens enterotoxin.

\section{Patients and methods}

\section{Patients}

All faecal specimens from single isolated cases of acute diarrhoea received by Ashford Public Health Laboratory in July and August 1991 were examined routinely for salmonellae, shigellae, campylobacters, aeromonas and cryptosporidium. Examination for $C$. difficile, Escherichia coli (ETEC and VTEC), Staphylococcus aureus and Bacillus cereus and their toxins, vibrios, yersiniae, parasites and viruses was done if indicated by clinical details--age, recent foreign travel, antibiotic treatment or the possibility of food

Received 2 March 1995; accepted 10 May 1995.

$\dagger$ Correspondence should be sent to Dr M. M. Brett. poisoning. All specimens from which no recognised enteropathogen was isolated were sent to the Food Hygiene Laboratory, Central Public Health Laboratory, Colindale, London for study.

\section{Enterotoxin detection}

One volume of faeces was mixed with up to four

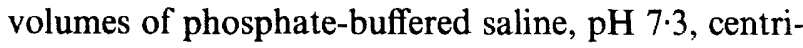
fuged at $20000 \mathrm{~g}$ for $20 \mathrm{~min}$ at $4^{\circ} \mathrm{C}$, filtered through a $0 \cdot 2-\mu \mathrm{m}$ membrane filter, then tested for $C$. perfringens enterotoxin with the Oxoid RPLA kit (Unipath). ${ }^{5-7}$ Positive and negative controls were included on each plate. All samples with a one-well or greater difference between agglutination with sensitised and control latex particles were tested by ELISA. ${ }^{5,8}$ Duplicate samples of each extract were incubated in triplicate for $75 \mathrm{~min}$ at room temperature with and without neutralising antibody before incubation for $70 \mathrm{~min}$ in plates that had been coated with rabbit IgG against enterotoxin and blocked with bovine serum albumin $1 \%{ }^{5,8}$ After washing, rabbit anti-enterotoxin conjugated to horseradish peroxidase was added, incubated for $2 \mathrm{~h}$, and removed by washing; then orthophenyldiamine in citrate phosphate buffer was added. The reaction was stopped with $100 \mu \mathrm{l}$ of $4 \mathrm{M} \mathrm{H}_{2} \mathrm{SO}_{4}$ and the absorbance was read at $492 \mathrm{~nm}$ in a microtitration plate reader (Titertek, Multiscan MCC 341; ICN-Flow Labora- 
tories Ltd, Herts). Wells containing no absorbed antibody or no test extract were included in each plate and gave an absorbance of $<0 \cdot 1$. A set of dilutions of an enterotoxin standard $(0.001-0.1 \mu \mathrm{g} / \mathrm{ml})$ on each plate was used to create a standard curve from which the enterotoxin concentration was calculated.

\section{Culture of C. perfringens}

$C$. perfringens spore counts were determined following alcohol shock. ${ }^{9}$ Serial 10 -fold dilutions of faecal suspensions after treatment with an equal volume of ethanol $95 \% \mathrm{v} / \mathrm{v}$ in distilled water were made in Maximum Recovery Diluent (Unipath) and plated on to Columbia Blood Agar plates according to a modified Miles and Misra method. ${ }^{10}$ Isolates were identified as $C$. perfringens by their reaction on Egg Yolk Nagler plates with anti- $C$. perfringens toxin A (Wellcome, Dartford). ${ }^{11}$

\section{Results}

During the 2-month study period, Ashford PHL received 370 faecal specimens from isolated, sporadic cases of diarrhoea. Enteropathogens other than $C$. perfringens were isolated from 99 specimens, which were excluded from this study, but not all faecal specimens were screened for all enteropathogens. There was insufficient sample for study in 59 cases and a total of 212 specimens was examined for $C$. perfringens enterotoxin.

The manufacturers make no recommendation as to whether a one-well or a two-well difference is considered positive. With the criterion of a two-well or more difference between agglutination of sensitised and control latex in the RPLA, enterotoxin was detected in 45 specimens. The positive results were confirmed by ELISA in 43 of the 45 specimens. A further 56 specimens gave a one-well difference in the RPLA; enterotoxin was confirmed by ELISA in 22 of these specimens. Thus, enterotoxin was detected by ELISA in a total of 65 of the 212 faecal specimens. A low concentration of enterotoxin was more common in specimens with a one-well difference in the RPLA ( $<0 \cdot 10 \mu \mathrm{g} / \mathrm{g}$ in 17 of the 22 samples) than in specimens with a two-well difference $(<0.10 \mu \mathrm{g} / \mathrm{g}$ in 17 of the 43 samples).

C. perfringens faecal spore counts were determined in 61 of the 65 enterotoxin-positive samples. Spore counts were $<10^{5} / \mathrm{g}$ of faeces in $42(69 \%)$ of the 61 samples. There was no correlation between spore count and enterotoxin concentration.

The ratio of male to female patients in enterotoxinpositive and enterotoxin-negative groups was similar (table). No age group predominated in either group, although one third of cases in both groups were $>60$ years old. A higher proportion of the enterotoxinpositive group was resident in the community $(71 \%)$ than of the enterotoxin-negative group, who were more commonly resident in hospital $(66 \%)$.

Information on antibiotic treatment was available for 132 patients. In both enterotoxin-positive and enterotoxin-negative groups, most patients had not received antibiotic therapy (table).

The duration of diarrhoea was known in 15 patients with enterotoxin-positive diarrhoea. In 12 cases, diarrhoea was prolonged: 3-6 days in three cases, 1-3 weeks in five cases and 4-6 weeks in four cases. Antibiotic treatment was also known in nine of these patients. One patient receiving antibiotics had diarrhoea which lasted for 2 weeks; eight patients were not treated and the duration of diarrhoea was 8-42 days, with a mean of 23.25 days.

\section{Discussion}

Faecal specimens from 370 cases of sporadic diarrhoea were examined but samples known to contain other pathogens were excluded because it would be difficult to interpret the significance of the presence of $C$. perfringens enterotoxin in addition to another enteropathogen such as a salmonella.

The Oxoid RPLA kit was used as a preliminary screening test to detect $C$. perfringens enterotoxin. The presence of enterotoxin was confirmed by ELISA in 43 of 45 specimens with a two-well or more difference in the RPLA and in 22 of 56 specimens with a one-well difference; thus, 65 of the 212 specimens were enterotoxin-positive. In the ELISA, extracts were pre-

Table. Comparison of patients with enterotoxin-positive and enterotoxin-negative faeces

\begin{tabular}{lcc}
\hline $\begin{array}{l}\text { Patient } \\
\text { characteristics }\end{array}$ & $\begin{array}{c}\text { Enterotoxin-positive } \\
\text { faeces (\%) }\end{array}$ & $\begin{array}{c}\text { Enterotoxin-negative } \\
\text { faeces (\%) }\end{array}$ \\
\hline $\begin{array}{l}\text { Number of patients } \\
\text { Number resident in }\end{array}$ & 65 & 147 \\
hospital & $19(29)$ & $97(66)$ \\
community & $46(71)$ & $50(34)$ \\
Antibiotic treatment & $4 / 37(11)$ & $16 / 95(17)$ \\
Ratio male/female* & $29: 35$ & $57: 89$ \\
C. perfringens spore count $<10^{5} / \mathrm{g}$ faeces & $42 / 61(69)$ & $\mathrm{NT}$ \\
\hline
\end{tabular}

NT, not tested.

*One unknown in each group. 
incubated with and without neutralising antibody against $C$. perfringens enterotoxin, to provide an internal blank for each specimen, so that the lower level of detection was $0.01-0.02 \mu \mathrm{g} / \mathrm{g}$ of faeces. ${ }^{5.7 .8}$ Two extracts were positive in the RPLA but this was not confirmed by ELISA. This could be due to errors inherent in the doubling dilutions used in the RPLA or because interference in the ELISA was not removed by the neutralising antibody. Enterotoxin was detected by ELISA in 22 extracts that gave a one-well difference in the RPLA. Non-specific interference was high in the RPLA in 11 of these specimens and the end-point for positive or control latex, or both, was unclear in seven extracts. In the remaining four specimens, the enterotoxin concentration was close to the lower level of detection of the RPLA. In the RPLA, a two-well difference is generally considered to be necessary to keep false-positive results to an acceptably low level, but positive samples with high levels of non-specific interference or with low enterotoxin levels may be missed. Interference by faecal constituents with enterotoxin detection in the RPLA has been reported in some $\mathrm{e}^{12,13}$ but not other ${ }^{7}$ studies, so that the maximum sensitivity may be only $0.05-0 \cdot 10 \mu \mathrm{g} / \mathrm{g}$ of faeces ${ }^{12.13}$ rather than $0.002-0.004 \mu \mathrm{g} / \mathrm{g}$ of faeces. ${ }^{7}$ The results presented here indicate that the use of a two-well difference in the RPLA may detect only two-thirds of enterotoxin-positive cases, whereas the use of a singlewell difference would result in a false-positive rate of c. $30 \%$.

The prevalence of $C$. perfringens enterotoxin in cases of sporadic diarrhoea in this study $(31 \%)$ was higher than that of an earlier study $(7 \%){ }^{5}$ This may be due in part to the inclusion in this study of specimens with a one-well difference in the RPLA. Faecal specimens in the present study were not screened for all entero-

\section{References}

1. Stringer MF. Clostridium perfringens type A food poisoning. In Borriello SP (ed) Clostridia in gastrointestinal disease. Florida, CRC Press. 1985: 117-143.

2. Borriello SP, Welch AR, Stringer MF, Larson HE, Barclay F, Bartholomew BA. Enterotoxigenic Clostridium perfringens: a possible cause of antibiotic-associated diarrhoea. Lancet 1984 ; 1 : 305-307.

3. Larson HE, Borriello SP. Infectious diarrhea due to Clostridium perfringens. $J$ Infect Dis 1988; 157: 390-391.

4. Luzzi I, Caprioli A, Bisicchia R, Ciammarugh R, Mastrantonio P. A sporadic case of diarrhoea due to enterotoxigenic Clostridium perfringens. Microbial Ecol Health Dis 1988; 1 69- 70 .

5. Brett MM, Rodhouse JC, Donovan TJ, Tebutt GM, Hutchinson DN. Detection of Clostridium perfringens and its enterotoxin in cases of sporadic diarrhoea. J Clin Pathol 1992: 45: 609-611.

6. Berry PR, Stringer MF, Uemura T. Comparison of latex agglutination and ELISA for the detection of Clostridium perfringens type A enterotoxin in faeces. Lett Appl Microbiol 1986; $2: 101-102$

7. Berry PR, Rodhouse JC, Hughes S, Bartholomew BA, Gilbert RJ. Evaluation of ELISA, RPLA, and Vero cell assays for detecting Clostridium perfringens enterotoxin in faecal specimens. J Clin Pathol 1988; 41: 458-461.

8. Bartholomew BA, Stringer MF, Watson GN, Gilbert RJ Development and application of an enzyme linked pathogens, so some may have contained pathogens other than $C$. perfringens. Furthermore, single point food sources of enterotoxigenic $C$. perfringens cannot be excluded in some cases. Diarrhoea was prolonged in 12 of 15 patients in whom information was available, which confirms the results of a previous study ${ }^{5}$ and is in contrast to $C$. perfringens food poisoning, in which diarrhoea generally resolves within $12-24 \mathrm{~h}$.

The proportions of males and females were similar in enterotoxin-positive and enterotoxin-negative diarrhoea, which confirms the findings of the earlier study, ${ }^{5}$ but in the present study a lower proportion of the enterotoxin-positive group were resident in hospital than of the enterotoxin-negative group.

C. perfringens spore counts in faeces were within the normal range, $<10^{5} / \mathrm{g}$, in $69 \%$ of enterotoxin-positive patients. High spore counts are found in most, but not all, patients associated with outbreaks of food poisoning ${ }^{14-17}$ but have also been reported in the faeces of healthy elderly people. ${ }^{18-20}$ Low numbers were unlikely to be due to loss of viability in vitro as spore counts are stable for weeks or months at $-20^{\circ} \mathrm{C}, 4^{\circ} \mathrm{C}$ and room temperature. ${ }^{17,19}$ There was no correlation between spore count and enterotoxin concentration.

This study confirms that enterotoxigenic $C$. perfringens is associated with sporadic diarrhoea in the absence of antibiotic treatment. A screening test to detect high numbers of $C$. perfringens spores is of limited value, and confirmation of diagnosis can be based only on the detection of the enterotoxin, but further work is needed to assess whether an acceptable accuracy of diagnosis is obtained with the RPLA or whether ELISA is necessary in all cases.

We are grateful to $\operatorname{Dr}$ R. J. Gilbert for his encouragement throughout this work.

immunosorbent assay for Clostridium perfringens type A enterotoxin. J Clin Pathol 1985; 38: 222-228.

9. Craven SE, Blankenship LC. Activation and injury of Clostridium perfringens spores by alcohols. Appl Environ Microbiol 1985; 50: 249-256.

10. International Commission on Microbiological Specifications for Foods. Micro-organisms in foods, 2nd edn, vol 1. Toronto, University of Toronto Press. 1978: 119-120.

11. Nakamura S, Shimamura T, Hayase M, Nishida S. Numerical taxonomy of saccharolytic clostridia, particularly Clostridium perfringens-like strains: descriptions of Clostridium absonum $\mathrm{sp}$. n. and Clostridium paraperfringens. Int J Syst Bacteriol 1973; 23 : 419-429.

12. Wimsatt JC, Harmon SM, Shah DS. Detection of Clostridium perfringens enterotoxin in stool specimens and culture supernatants by enzyme-linked immunosorbent assay. Diagn Microbiol Infect Dis 1986; 4: 307-313.

13. Harmon SM, Kautter DA. Evaluation of a reversed passive latex agglutination test kit for Clostridium perfringens enterotoxin. J Food Protect 1986; 49: 523-525.

14. Sutton RGA, Hobbs BC. Food poisoning caused by heatsensitive Clostridium welchii. A report of five recent outbreaks. J Hyg 1965; 66: 135 146.

15. Harmon SM, Kautter DA, Hatheway CL. Enumeration and characterisation of Clostridium perfringens spores in the faeces of food poisoning patients and normal controls. $J$ Food Protect 1986; 49: 23-38.

16. Birkhead G, Vogt RL, Heun EM, Snyder JT, McClane BA. Characterization of an outbreak of Clostridium perfringens food poisoning by quantitative fecal culture and fecal 
enterotoxin measurement. $J$ Clin Microbiol 1988; 26: 471-474.

17. Labbe R. Clostridium perfringens. In: Doyle MP (ed) Foodborne bacterial pathogens. New York, Marcel Dekker Inc. 1989: 191-234.

18. Yamagishi T, Serikawa T, Morita R, Nakamura S, Nishida S. Persistent high numbers of Clostridium perfringens in the intestines of Japanese aged adults. Jpn J Microbiol 1976; 20: 397-403.

19. Stringer MF, Watson GN, Gilbert RJ et al. Faecal carriage of Clostridium perfringens. J Hyg 1985; 85: 277-288.

20. Samuel SC, Hancock P, Leigh DA. An investigation into Clostridium perfringens enterotoxin-associated diarrhoea. $J$ Hosp Infect 1991; 18: 219-230. 